\title{
Copper complex of isatin Schiff base encapsulated in zeolite as active heterogeneous catalyst: an efficient protocol for the acetylation reaction
}

\author{
B. P. Nethravathi ${ }^{1} \cdot$ P. Manjunathan ${ }^{2}$ K. N. Mahendra ${ }^{2}$
}

Published online: 26 April 2016

(C) Springer Science+Business Media New York 2016

\begin{abstract}
Copper (II) complex of 3-phenylimino-1,3-dihydro-indol-2-one encapsulated in the super cages of zeolite-Y has been synthesized by flexible ligand method and characterized by various physicochemical measurements. The catalytic activity of cationic exchanged zeolite, copper complex of ligand and complex encapsulated inside the zeolite was investigated for the decomposition of $\mathrm{H}_{2} \mathrm{O}_{2}$ and for the acetylation of $p$-cresol. All catalysts show good to excellent yield. The results showed that conversion of $p$-cresol varies in the order homogeneous complex $<\mathrm{Na}$ Y-Zeolite $<\mathrm{Cu}$-Y-Zeolite $<$ heterogeneous complex.
\end{abstract}

Keywords Encapsulation · Zeolite-Y · Catalyst · Hydrogen peroxide $\cdot$ Decomposition · Acetylation

\section{Introduction}

The well-defined cages and channels of the zeolite serve as a sort of reaction flask with suitable molecular dimension for the encapsulation of metal complexes. During the last two decades an increasing number of publications have appeared reporting the use of zeolites as solid catalysts for liquid phase reactions for the production of fine chemicals.

Electronic supplementary material The online version of this article (doi:10.1007/s10934-016-0189-9) contains supplementary material, which is available to authorized users.

K. N. Mahendra

knmahendra@gmail.com

1 Department of Chemistry, Vijaya College, R.V. Road, Bangalore 560 004, India

2 Department of Chemistry, Bangalore University, Bangalore 560 001, India
The encapsulation of transition metal complexes which are catalytically active in solution phase, in zeolite pores; usually X-and Y-zeolite has been well established [1-6]. They have more applications in the synthesis of fine chemicals and are being used in various types of catalytic reactions such as oxidation, alkylation and dehydrogenation [7-11] to produce major industrial products. These encapsulated metal complexes in zeolites played considerable role in the hydroxylation of phenol using simple oxidants such as molecular oxygen and $\mathrm{H}_{2} \mathrm{O}_{2}[12,13]$. Though hydrogen peroxide is more expensive than oxygen, it can be the oxidant of choice because of its simplicity of operation, i.e. in fine chemical and pharmaceutical use, the total cost of equipment and raw material may be lower for oxidation employing hydrogen peroxide over oxygen [14].

The need for cleaner processes, many new and interesting technologies are emerging, especially in fine chemicals where high selectivity to the desired product is crucial. Therefore, the design of novel heterogeneous technologies is gaining importance in the enantioselective oxidations and in different organic transformations.

In this work, studies on the synthesis and characterization of zeolite $\mathrm{Y}$ encapsulated complex of $\mathrm{Cu}$ (II) with 3-phenylimino-1,3-dihydro-indol-2-one is presented. The structure of the ligand is shown in Scheme 1. Application of the complexes for acetylation of $p$-cresol was studied and the results of these studies are discussed.

\section{Experimental}

\subsection{Materials}

Analytical grade metal salts such as copper nitrate and sodium chloride purchased from Merck and Isatin 


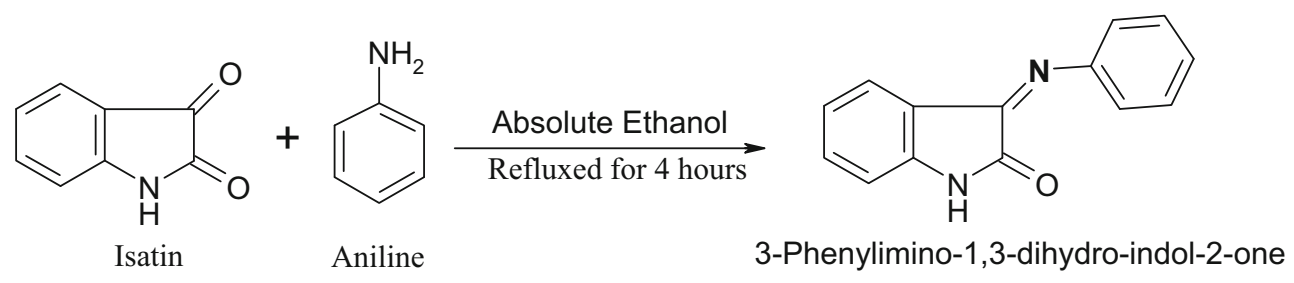

Scheme 1 Synthesis of 3-phenylimino-1,3-dihydro-indol-2-one

purchased from Spectrochem PVT. LTD., Aniline, which were used for complex preparation. The solvent used were purified by standard procedures [15]. Sodium form of Na-Y-Zeolite was purchased from Sud to Chemie, Mumbai. $p$-cresol, acetic anhydride, $30 \%$ hydrogen peroxide used are of analytical grade.

\subsection{Physicochemical characterization}

The surface areas of the zeolite samples were determined by the BET method of nitrogen adsorption at liquid nitrogen temperature by BET method on a NOVA-1000 Ver. 3.70 instrument. Powder X-ray diffraction patterns of zeolite $\mathrm{Na}-\mathrm{Y}$ and the zeolite encapsulated complex were recorded using Philips X'Pert diffractometer using CuKa $(\mathrm{k}=0.15405 \mathrm{~nm})$ target with nickel filter. The morphology of the sample was examined using Philips scanning electron microscopy. Infrared spectra of the ligand, simple complex and supported complexes in the region $4000-400 \mathrm{~cm}^{-1}$ were recorded as $\mathrm{KBr}$ pellet on a FTIR8400S Shimadzu, spectrophotometer. Thin layer chromatographic technique was used to analyze the reaction products of the catalytic activity studies.

\subsection{Synthesis of complexes}

\subsubsection{Synthesis of 3-phenylimino-1,3-dihydro-indol-2-one}

The Schiff base ligand was prepared by reported method [16]. $0.001 \mathrm{~mol}$ of isatin and $0.001 \mathrm{~mol}$ of aniline were dissolved in ethanol and refluxed for about $4 \mathrm{~h}$. The progress of the reaction was monitored by thin layer chromatography. Then the above reaction mixture is poured into a beaker containing ice cold water with constant stirring and allowed to settle and then the yellow coloured ligand was collected by filtration and recrystallized from ethanol. The M.P. of ligand was found to be $223{ }^{\circ} \mathrm{C}$.

\subsubsection{Synthesis of homogeneous metal complex}

Equimolar mixture of copper nitrate and ligand was dissolved in absolute alcohol and refluxed for $4 \mathrm{~h}$. Then the reaction mixture was concentrated, filtered and dried. The obtained brown colour complex has Melting Point $>352{ }^{\circ} \mathrm{C}$.

\subsubsection{Synthesis of heterogeneous catalyst}

It involves two stages.

2.3.3.1 Synthesis of copper exchanged zeolite-Y Sodium form of zeolite-Y (Na-Y) of $11 \mathrm{~g}$ sample was stirred in $100 \mathrm{ml}$ ethanolic solution of copper nitrate of $5 \mathrm{~g}$ at $80{ }^{\circ} \mathrm{C}$ for $12 \mathrm{~h}$. Metal exchanged zeolite was washed with distilled water till the filtrate was free from copper ions. The metal exchanged zeolite was dried at $150{ }^{\circ} \mathrm{C}$ for $3 \mathrm{~h}$. Colour of the copper exchanged zeolite-Y was observed to be a pale green colour.

\subsubsection{Synthesis of zeolite-Y encapsulated transition metal} complex Metal exchanged $\mathrm{Cu}-\mathrm{Y}$-zeolite $(7 \mathrm{~g})$ was added to a solution of the ligand $(4.5 \mathrm{~g})$. The mixture was refluxed with stirring for $24 \mathrm{~h}$ on an oil bath. The ligand penetrates through the channels of zeolite and complex is formed. The product obtained was soxhlet extracted using a suitable solvent to remove excess ligand and surface species. The soxhlet extraction was continued until extract becomes colourless indicating complete removal of the species to be eliminated. The uncomplexed metal remaining in the zeolite was removed by back exchange of zeolite with $\mathrm{NaCl}$ solution $(0.1 \mathrm{M})$ by stirring for $24 \mathrm{~h}$. It was then filtered, washed free of chloride ions, and finally dried at $150{ }^{\circ} \mathrm{C}$ for $24 \mathrm{~h}$ to get the required encapsulated complexes [17].

\subsection{Catalytic activity measurements}

\subsubsection{Decomposition of $\mathrm{H}_{2} \mathrm{O}_{2}$}

The catalysts were activated by heating to $120{ }^{\circ} \mathrm{C}$ for $2 \mathrm{~h}$. $3.95 \mathrm{ml}$ of $30 \% \mathrm{H}_{2} \mathrm{O}_{2}$ was added to $25 \mathrm{mg}$ of catalyst and it was stirred for 1 and $2 \mathrm{~h}$ at room temperature respectively. The catalyst was then filtered and washed with distilled water. The filtrate containing partially decomposed $\mathrm{H}_{2} \mathrm{O}_{2}$ and the washing were collected in a $250 \mathrm{ml}$ volumetric flask, and then made up to the mark with 
distilled water. Then $10 \mathrm{ml}$ of this solution was titrated against a standard $\mathrm{KMnO}_{4}(0.05 \mathrm{~N})$ solution to estimate the unreacted $\mathrm{H}_{2} \mathrm{O}_{2}$ [18].

\subsubsection{Acetylation of p-cresol (solvent free reaction)}

The reaction was carried out in a $50 \mathrm{ml}$ double necked round bottom flask fitted with a water cooled condenser. In a typical reaction, $p$-cresol $(5 \mathrm{mmol}, 0.5406 \mathrm{~g})$, acetic anhydride $(7.5 \mathrm{mmol}, 0.7656 \mathrm{~g})$ and $0.5 \mathrm{~g}$ of catalyst was added and stirred at room temperature for constant stirring. The progress of the reaction was monitored by TLC, and the mixture was diluted with sodium bicarbonate $(10 \%$; $15 \mathrm{ml})$, then extracted with dichloromethane $(20 \times 3)$. Organic layer was evaporated to dryness to afford the acetylated product.

\subsubsection{Recycling of the catalyst}

At the end of the reaction, catalyst was filtered washed with dichloromethane, dried at $110{ }^{\circ} \mathrm{C}$ for $1 \mathrm{~h}$. Then it is used for acetylation reaction under optimized condition.

\section{Results and discussion}

\subsection{Synthesis and characterization of catalysts}

Synthesis of the metal complexes encapsulated in the zeolite cages of $\mathrm{Na}-\mathrm{Y}$ was carried out by the flexible ligand method [19]. To compare the properties of the encapsulated complexes, the metal exchanged zeolite and neat complexes of $\mathrm{Cu}$ (II) with ligand were also prepared and characterized by various physicochemical techniques. The analytical data obtained were in good agreement with the data available in literature [20]. The significant reduction in surface area and pore volume as a result of encapsulation of complexes within the zeolite pores is due to the blocking of the pores by the formation of the metal complexes. The decrease in surface area values suggests the formation of metal complexes inside the zeolite cages [Table 1].

\subsection{FTIR spectra}

Infrared spectroscopy was used for the identification of functional groups, and for detecting the coordination of ligand to transition metal. Hence, it can be used as an effective tool to confirm the formation of the complexes within in the zeolite pores and to detect the coordination of ligand to the transition metal. Infrared spectra of the ligand, neat complex and supported complex in the region $4000-400 \mathrm{~cm}^{-1}$ were recorded on a FTIR-8400S Shimadzu, spectrophotometer instrument. The characteristic bands due to the coordination sites of ligand exhibits well defined shift upon complexation. But many of these bands may be masked by strong bands of zeolite in zeolite encapsulated complex. The framework vibrations of zeolite are observed in the spectral range between $1250-400 \mathrm{~cm}^{-1}$.

The comparative analysis of the IR spectra of the free ligand and the new obtained complexes offers important information about the type of the coordination process between metallic ions and organic ligand. The most important absorption bands in the IR spectra of the ligand and its complexes are given in Table 2. In the IR spectra of the ligand, medium intensity bands are observed in the spectral region $3500-3400 \mathrm{~cm}^{-1}$; these bands may be assigned to the vibration modes of $\mathrm{NH}$ groups from isatin ring. In the double bonds region are presented bands at 1749 and $1647 \mathrm{~cm}^{-1}$. These bands are specific stretching frequencies of the carbonyl and azomethine groups. Comparing the bands in the double bonds region, the IR spectra of the complex and the ligand, important differences are observed. The characteristic bands for $\mathrm{C}=\mathrm{O}$ and $\mathrm{C}=\mathrm{N}$ groups are shifted to lower values than ligand, that suggest their involvement in the coordination process. The bands due to vibration mode $\mathrm{NH}$ are practically unchanged in the spectra of the complexes, suggested that $\mathrm{NH}$ group is not involved in the coordination process. We also observed a band of medium intensity in the region $3539 \mathrm{~cm}^{-1}$, characteristic for the $\mathrm{OH}$ groups belonging to water molecules in the structure of the compounds, indicating a coordination of the water molecules at the central metallic ion [21, 22]. The IR spectral data suggest for the ligand a bidentate neutral behaviour, by participating in the coordination with the azomethine nitrogen atom and the oxygen atom of the carbonyl group.

\subsection{Powder X-ray diffraction studies}

The powder X-ray diffraction patterns of $\mathrm{H}-\mathrm{Y}$ and the encapsulated complexes were recorded at $2 \theta$ values of $5^{\circ}-$
Table 1 Surface area measurement data

\begin{tabular}{llll}
\hline S1. no. & Compound & Surface area $\left(\mathrm{m}^{2} / \mathrm{g}\right)$ & $\begin{array}{l}\text { Pore volume } \\
(\mathrm{cc} / \mathrm{g})\end{array}$ \\
\hline 1 & $\mathrm{Z}-\mathrm{Y}$ & 25.80 & 0.105 \\
2 & Heterogeneous complex & 20.74 & 0.093 \\
\hline
\end{tabular}


Table 2 Absorbtion bands in the IR spectra of the ligand and its complexes

\begin{tabular}{llllll}
\hline Sl. no. & Ligand/complex & $\mathrm{v}_{\mathrm{OH}}\left(\mathrm{cm}^{-1}\right)$ & $v_{\mathrm{NH}}\left(\mathrm{cm}^{-1}\right)$ & $v_{\mathrm{C}=\mathrm{O}}\left(\mathrm{cm}^{-1}\right)$ & $v_{\mathrm{C}=\mathrm{N}}\left(\mathrm{cm}^{-1}\right)$ \\
\hline 1 & Ligand & 3465 & 1749 & 1647 \\
2 & Copper complex & 3539 & 3463 & 1741 & 1627 \\
\hline
\end{tabular}

$80^{\circ}$ (Fig. 1). Similar patterns are formed for the encapsulated complexes as compared to the starting zeolite Na-Y, though slight changes in the intensity of the bands are seen. These observations indicate that the crystalline nature of the zeolite is retained even after the encapsulation of the complex. No new peaks were detected in the XRD patterns of the encapsulated complex possibly due to the presence of low content of the metal complexes.

\subsection{Catalytic studies}

The synthesized complexes were screened for catalytic activities for some well-known reactions. Screening studies of the zeolite encapsulated complex for the decomposition of $30 \% \mathrm{H}_{2} \mathrm{O}_{2}$ was studied and details regarding the procedure adopted are given in chapter. The complex was screened for the catalytic activity in the acetylation of $p$-cresol. Thin layer chromatography technique was employed for catalytic activity studies.

\subsubsection{Thin layer chromatography}

Glass plates were coated with silica gel (adsorbent) and activated in oven at $110{ }^{\circ} \mathrm{C}$ and used for thin layer chromatography. The substance to be separated was spotted near one end of the adsorbed layer and was placed vertically in a jar containing a suitable solvent mixture of solvents. The solvent passes through the adsorbed layer as per the principle of capillary action. The plate was taken out from the jar and kept in air.

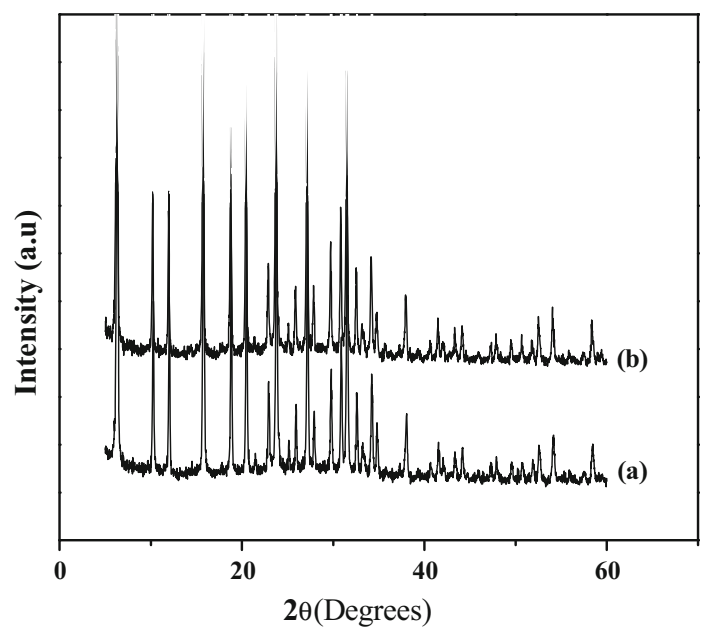

Fig. 1 PXRD patterns of zeolite-Y and its encapsulated complex. $a \mathrm{Z}-\mathrm{Y}$ and $b$ Heterogeneous complex

\subsubsection{Decomposition of $\mathrm{H}_{2} \mathrm{O}_{2}$}

The catalytic activity for the decomposition of $\mathrm{H}_{2} \mathrm{O}_{2}$ with the encapsulated complexes was studied. The quantity of $\mathrm{H}_{2} \mathrm{O}_{2}$ that reacted at two different time intervals (1 and $2 \mathrm{~h}$ ) were measured. The results tabulated in Table 3, show that the decomposition of $\mathrm{H}_{2} \mathrm{O}_{2}$ is slow initially but increases with time. This is due to the fact that the encapsulated complex used requires relatively longer time to exhibit maximum catalytic activity as number of metal centres is less compared to that of the neat complex. Hence increasing the duration of the reaction is a very effective way of carrying out the reaction with $\mathrm{H}_{2} \mathrm{O}_{2}$ as the source of oxygen.

From the above data it is found to be, the metal complex gives high activity towards catalytic decomposition of $\mathrm{H}_{2} \mathrm{O}_{2}$, due to the presence of more active sites in metal complex. Followed by the metal complex, the heterogeneous complex shows comparatively more activity when compared to Na-Y-zeolite and $\mathrm{Cu}(\mathrm{ll})-\mathrm{Y}$-zeolite. And less activity when compared to metal complex due to presence of less active site on heterogeneous complex.

Blank run the decomposition reaction was studied under conditions identical with those of catalytic activity experiments without adding the catalysts. There was no measurable decomposition of hydrogen peroxide.

\subsubsection{Acetylation of p-cresol}

The acetylation of $p$-cresol using different encapsulated complexes was studied as a function of time using acetic anhydride as acetylating agent. p-cresyl acetate was obtained as the major products, as shown in Scheme 2.

The reaction was carried out for the optimized condition ( $5 \mathrm{mmol} p$-cresol, acetic anhydride $7.5 \mathrm{mmol}, 0.05 \mathrm{~g}$ catalyst at room temperature) for all catalysts. The effect of different catalysts on the percentage conversion of $p$-cresol is tabulated in Table 4. It clearly indicates that maximum $p$-cresol conversion is observed with heterogeneous catalyst.

The maximum conversion of $p$-cresol obtained is with zeolite encapsulated complex by less time compared to other catalyst. The order of catalytic activity for acetylation of $p$-cresol is found to be as follows heterogeneous catalyst $(75 \%)>[\mathrm{Cu}-\mathrm{Y}]$ zeolite $(55 \%)>[\mathrm{Na}-\mathrm{Y}]$ zeoite $(50 \%)>$ homogeneous catalyst $(65 \%)>$ without catalyst $(50 \%)$ under optimised reaction condition. 
Table 3 Percentage decomposition of $\mathrm{H}_{2} \mathrm{O}_{2}$

\begin{tabular}{lllll}
\hline S1. no. & Catalyst used & Amount $(\mathrm{g})$ & \multicolumn{2}{l}{$\%$ Decomposition of $30 \% \mathrm{H}_{2} \mathrm{O}_{2}$} \\
\cline { 4 - 5 } & & After $1 \mathrm{~h}$ & After $2 \mathrm{~h}$ \\
\hline 1 & Homogeneous & 0.025 & 4.25 & 5.69 \\
2 & Na-Y-zeolite & 0.025 & 0.33 & 1.26 \\
3 & Cu-Y-Zeolite & 0.025 & 0.99 & 1.49 \\
4 & Heterogeneous & 0.025 & 1.41 & 1.99 \\
\hline
\end{tabular}

Scheme 2 Acetylation of p-cresol

Table 4 Percentage conversion of $p$-cresol

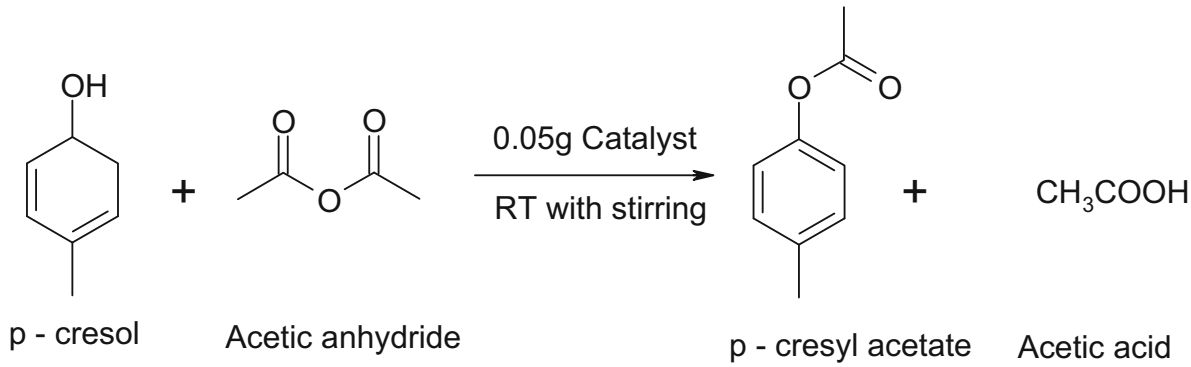

\begin{tabular}{llcl}
\hline Catalyst & Weight $(\mathrm{g})$ & Time $(\mathrm{min})$ & \% Conversion of $p$-cresol \\
\hline Without catalyst & - & 140 & 50 \\
Homogeneous & 0.05 & 90 & 65 \\
Na-Y-Zeolite & 0.05 & 105 & 50 \\
Cu-Y-Zeolite & 0.05 & 90 & 55 \\
Heterogeneous & 0.05 & 70 & 75 \\
\hline
\end{tabular}

\subsubsection{Recycling test}

Phenol hydroxylation reaction was carried out by using recycled catalyst for the zeolite encapsulated complex. After the completion of the reaction with fresh catalyst, the catalyst was filtered, washed with acetone and then dried at $110^{\circ} \mathrm{C}$. Then the recycled catalyst was used again to test its catalytic activity for acetylation of $p$-cresol by conducting the reaction under the same reaction conditions which was optimized for a particular ligand as explained earlier. A comparison of the percentage conversion of phenol for the fresh and the recycled catalysts shows that there is small decrease in the activity of recycled catalysts may be because of the presence of adsorbed molecules. But the selectivity for the product formation remains almost unaltered.

\section{Conclusions}

$\mathrm{Cu}$ (II) complex of 3-phenylimino-1,3-dihydro-indol-2-one have been encapsulated in the super cages of zeolite-Y. Physicochemical analysis gave clear evidence for their encapsulation. This was confirmed by running a blank reaction. No leaching of metal ions was detected in the solution. The influence of different parameters such as the amount of catalyst, temperature, time etc., was studied and these factors show different catalytic activities in the decomposition of $\mathrm{H}_{2} \mathrm{O}_{2}$ and acetylation of $p$-cresol. Copper encapsulated zeolite complex (heterogeneous catalyst) shows maximum conversion of $75 \%$. Comparable IR and XRD patterns of fresh and used encapsulated catalysts suggest that these can be used further for catalytic study. Hence the heterogeneous catalyst has very high activity towards acetylation of $p$-cresol in addition to good conversion rate in fewer periods when compared to homogeneous catalyst, copper exchanged zeolite, Sodium form of zeolite $\mathrm{Y}$ in solvent free condition.

Acknowledgments The authors gratefully acknowledge Prof. Ramakrishna Reddy, Department of Chemistry, Government Science College, Bangalore for his valuable suggestion for carrying out this research work.

\section{References}

1. H. Diegrilber, P.J. Plath, G. Schulz-Ekloff, J. Mol. Catal. 24, 115 (1984)

2. N. Herron, Inorg. Chem. 25, 4714 (1986) 
3. N. Herron, G.D. Stucky, C.A. Tolman, J. Chem. Soc. Chem. Commun. 20, 1521 (1986)

4. N. Herron, C.A. Tolman, J. Am. Chem. Soc. 109, 2837 (1987)

5. G.A. Ozin, C. Gil, Chem. Rev. 89, 1749 (1989)

6. F. Bedioui, Coord. Chem. Rev. 144, 39 (1995)

7. B.P. Nethravathi, K.N. Mahendra, J. Porous Mater. 17(1), 107 (2010)

8. K.K. Fodor, G.A. Sebastiaan, R.A. Sheldon, Enantiomer 4, 497 (1999)

9. G.J. Hutchings, Chem. Commun. 4, 301 (1999)

10. J.S. Rafelt, J.H. Clark, Catal. Today 57, 3 (2000)

11. R.A. Sheldon, I.W.C.E. Arends, A. Dijksman, Catal. Today 57, 157 (2000)

12. S. Seelan, A.K. Sinha, D. Srinivas, S. Sivasanker, Bull. Catal. Soc. India 1, 29 (2002)

13. B.P. Nethravathi, K.N. Mahendra, J. Porous Mater. 17, 107 (2010)

14. Q. Yang, C. Li, S. Yuan, J. Li, P. Ying, Q. Xin, W. Shi, J. Catal. 183, 128 (1999)
15. D.D. Perrin, W.L.F. Armanego, D.R. Perrin, Purification of Laboratory Chemicals (Pergamon Press, Oxford, 1966)

16. N. Raman, S. Sobha, J. Serbian Chem. Soc. 75(6), 773 (2010)

17. B.P. Nethravathi, K. Rama Krishna Reddy, K.N. Mahendra, J. Porous Mater. 21, 285 (2014)

18. J. Bassett, R.C. Denney, G.H. Jeffery, J. Mendham, Vogel's Textbook of Quantitative Inorganic Analysis, 4th edn. (Longman Scientific and Technical, London, 1978)

19. C. Subrahmanyam, B. Louis, B. Viswanathan, A. Renken, T.K. Varadarajan, Bull. Catal. Soc. India 3 (2004)

20. M. Verma, S.N. Pandeya, K.N. Singh, J.P. Stables, Acta Pharm. 54(1), 49 (2004)

21. A.P. Mishra, R. Mishra, R. Jain, S. Gupta, Mycobiology 40(1), 20 (2012)

22. R. Rao, K.R. Reddy, K.N. Mahendra, Bul. Chem. Commun. 46(1), 11 (2014) 